\title{
Poor access to kidney disease management services in susceptible patient populations in rural Australia is associated with increased aeromedical retrievals for acute renal care
}

\author{
Fergus W. Gardiner (D, , ${ }^{1,2}$ Lara Bishop, ${ }^{1}$ Lauren Gale, ${ }^{1}$ Abby Harwood, ${ }^{1}$ Narci Teoh, ${ }^{3}$ Robyn M. Lucas, ${ }^{2}$ \\ Martin Jones ${ }^{4}$ and Martin Laverty ${ }^{1}$ \\ ${ }^{1}$ The Royal Flying Doctor Service, ${ }^{2}$ National Centre for Epidemiology and Population Health and The Australian National University Medical School, The \\ Australian National University Canberra, ${ }^{3}$ Medicine and Surgery Program, The Australian National University Medical School at The Canberra Hospital \\ Canberra, Australian Capital Territory, and ${ }^{4}$ University of South Australia Department of Rural Health Whyalla, South Australia, Australia
}

\section{Key words}

chronic kidney disease, delivery of health care, emergency medicine, general medicine, rural health services.

Correspondence Fergus W. Gardiner, Royal Flying Doctor Service, Level 2, 10-12 Brisbane Avenue, Barton, ACT 2600, Australia.

Email: fergus.gardiner@rfds.org.au

Received 15 May 2019; accepted 25 November 2019.

\begin{abstract}
Background: Inequalities in access to renal services and acute care for rural and remote populations in Australia have been described but not quantified.

Aim: To describe: the coverage of renal disease management services in rural and remote Australia; and the characteristics of patients who had an aeromedical retrieval for renal disease by Australia's Royal Flying Doctor Service (RFDS).

Methods: Data from the RFDS, the Australian Bureau of Statistics, and Health Direct were used to estimate provision of renal disease management services by geographic area. RFDS patient diagnostic data were prospectively collected from 2014 to 2018.

Results: Many rural and remote areas have limited access to regular renal disease management services. Most RFDS retrievals for renal disease are from regions without such services. The RFDS conducted 1636 aeromedical retrievals for renal disease, which represented $1.6 \%$ of all retrievals. Among retrieved patients, there was a higher proportion of men than women $(54.6 \%$ vs $45.4 \%, P<0.01)$, while indigenous patients $(n=$ $546,33.4 \%$ ) were significantly younger than non-indigenous patients (40.9 vs 58.5 , $P<0.01)$. There were significant differences in underlying diagnoses triggering retrievals between genders, with males being more likely than females to be transferred with acute renal failure, calculus of the kidney and ureter, renal colic, obstructive uropathy, and kidney failure (all $P<0.01$ ). Conversely, females were more likely to have chronic kidney disease, disorders of the urinary system, acute nephritic syndrome, tubulo-interstitial nephritis, and nephrotic syndrome (all $P<0.01$ ).

Conclusion: Aeromedical retrievals for acute care were from rural areas without regular access to renal disease prevention or management services.
\end{abstract}

\section{Introduction}

Similar to countries of vast expanse such as North America and China, ${ }^{1,2}$ Australian populations living in rural and remote regions typically have poorer health compared to those living in major cities. ${ }^{3}$ Rural and remote Australians have a higher prevalence of disease risk factors, such as smoking, overweight and obesity, and alcohol and drug misuse compared to major cities. ${ }^{4}$ Furthermore, there is reduced access to health care and long distances to travel to receive medical services. ${ }^{3}$ These factors, in combination, result in higher rates of chronic diseases, increased morbidity and mortality for

Funding: None.

Conflict of interest: None. people living in rural and remote regions compared to those living in major cities. ${ }^{5-7}$

The major discrepancies in mortality from chronic diseases between rural and remote and urban settings are 1.3 times higher mortality from coronary heart disease and 2.3 times higher death from diabetes. These diseases in turn are associated with an increased risk of chronic kidney disease $(\mathrm{CKD}){ }^{8}{ }^{8}$ Reduction in morbidity and mortality rests firstly on prevention - the reduction of risk factors - and then on the adequacy of treatment. The risk factors for CKD are similar to those for a range of other chronic diseases: smoking, limited physical activity, obesity and hypertension. The prevalence of these risk factors is higher in rural and remote than urban populations, representing a clear opportunity for prevention. ${ }^{9-11}$ In addition, access to health care may be 
limited in rural and remote regions; that is, both prevention and treatment which are likely to contribute to health disparities for rural and remote populations.

Aboriginal and Torres Strait Islander (hereafter referred to as indigenous) Australians have worse health outcomes when compared to non-indigenous Australians on many metrics, and this is compounded for Indigenous Australians living in rural and remote regions. A recent study of an indigenous population in a remote area of Western Australia highlighted the leading causes of death were diabetes, renal failure and ischaemic heart disease. For diabetes and renal failure, mortality was much higher than the general Australian population (16\% vs $2.9 \% ; 12 \%$ vs $1.8 \%$, respectively). ${ }^{12}$

In this article, we focus on renal diseases and access of Australians living in rural and remote areas to appropriate health services. We use data on the location of renal disease management services as a measure of access to relevant services, and the impact on aeromedical retrievals for emergent care.

The specific aims of this article are to:

1 map the location of renal disease management services available to people living in rural and remote areas of Australia; and

2 describe the characteristics of patients who underwent aeromedical retrieval (gender, indigenous status and age) for renal diseases between July 2014 and June 2018.

\section{Methods}

\section{Setting}

The Royal Flying Doctor Service (RFDS) provides essential aeromedical and primary healthcare to rural and remote populations and visitors who are unable to access traditional services, such as those involving the Medicare Benefits Schedule (MBS). As with other literature, ${ }^{13-15}$ the terms 'rural' and 'remote' include all areas outside Australia's major cities, including areas classified as inner and outer regional (RA2 and RA3 respectively) and remote or very remote (RA4 and RA5 respectively) by the Australian Statistical Geography Standard (ASGS). ${ }^{16}$

\section{Data sources}

We used data from the Australian Bureau of Statistics (ABS) 2016 Census to derive geographical population estimates. We defined 'renal disease management services' as including renal disease management units, dialysis and renal services/units, and Aboriginal Health Services, as registered on Health Direct. For an extensive list, please refer to Health Direct. ${ }^{17}$ We then used the Service Planning and Operational Tool (SPOT) to map coverage of renal disease management services across Australia, with a focus on rural and remote Australia. Working from a geographic distribution of 'demand (population)' and a set of healthcare facilities that provides cover for a range of services (in this case - renal disease management services), SPOT calculates the proportion of demand covered by those facilities within a user-specified drive time. ${ }^{14}$ Demand is represented by population levels in different categories (e.g. renal disease patients).

For the second aim, we used data on patients who had an aeromedical retrieval between July 2014 and June 2018. Data were prospectively collected on each patient's inflight working diagnosis, and coded to the International Statistical Classification of Diseases and Related Health Problems, Tenth Revision, Australian Modification (ICD-10-AM). ${ }^{18,19}$ In this analysis, we included all patients with a diagnosis of renal disease, ICD-10 codes N00-N29 (diseases of the kidney). Data were collected within flight on the patient's gender, age, and indigenous status, using either paper-based or electronic methods, according to the usual practice of the specific RFDS Section and Operation.

RFDS clinical and aeromedical databases were also accessed to provide patient flight information, including the number of patient flight legs. Multiple transfer legs were removed from the analysis and reduced to a single episode of care.

This project was deemed a low-risk quality assurance project by the RFDS Clinical and Health Services Research Committee (CHSRC), on 18 March 2019. As this project involved routinely collected data, specific patient consent forms were not required.

\section{Statistical analysis}

A combination of descriptive statistics and Chi-squared analysis was used in data analysis, with significance determined at $P<0.01$. All analyses were performed using Microsoft Excel and the statistical software package $R$ version 3.5.1.

\section{Results}

Mapping of the registered renal disease management services indicate that there are many rural and remote areas that do not have permanent clinical provision, such as the rural and remote regions of Whyalla (26 460 people without access), Norseman (14761 people 


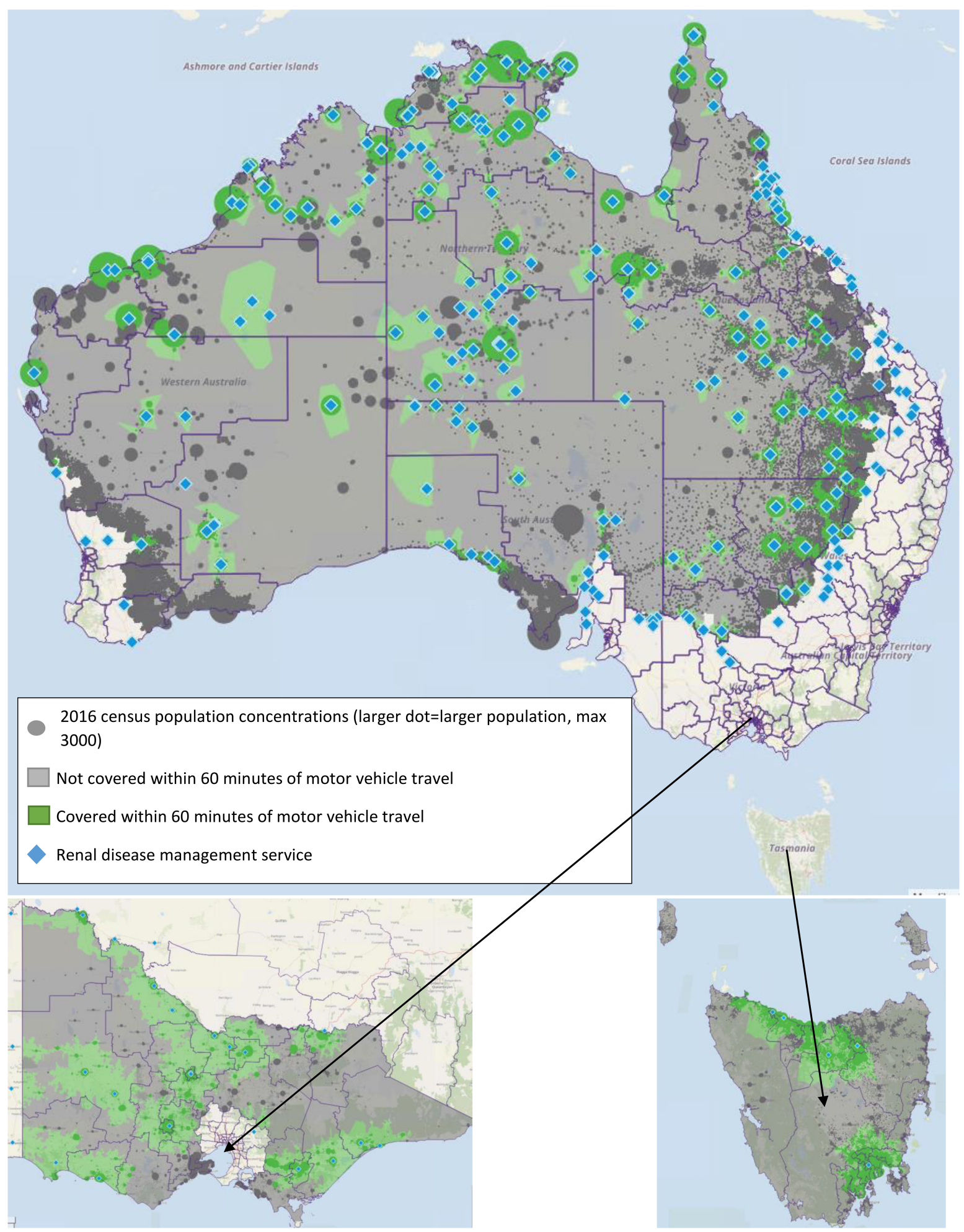

Figure 1 Rural and remote renal disease management service locations and corresponding population concentrations. This figure estimates the rural and remote provision of renal disease management services, and excludes metropolitan areas, using HealthDirect (renal disease management services, including dialysis unit and Aboriginal Medical Services), RFDS and ABS data sources. The dots indicate population concentrations, with larger dots equalling more people (max 3000). Green dots indicate population concentrations that are able to access services within a 60 min drive time; grey dots indicate population concentrations that are not able to access services within a 60 min drive time. 
Gardiner et al.

Table 1 Study characteristics and yearly trends

\begin{tabular}{|c|c|c|c|c|c|}
\hline & $2014 / 15$ & $2015 / 16$ & $2016 / 17$ & $2017 / 18$ & Total \\
\hline $\begin{array}{l}\text { Total renal disease diagnosis: ICD-10 codes N00-N29 (\% of total } \\
\text { retrievals) }\end{array}$ & $238(2.0)$ & $241(0.8)$ & $543(1.85)$ & $614(1.8)$ & $1636(1.6)$ \\
\hline Mean age (SD) (years) & $51.9(23.4)$ & $53.1(22.8)$ & $52.1(21.3)$ & $52.9(21.7)$ & $52.7(22.2)$ \\
\hline Male $(\%)$ & $133(55.9)$ & $125(51.9)$ & $303(55.8)$ & $332(54.1)$ & $893(54.6)$ \\
\hline Indigenous (\%) & 87 (36.5) & $83(34.4)$ & $180(33.1)$ & $196(31.9)$ & $546(33.4)$ \\
\hline Total retrievals & 11760 & 30151 & 29319 & 33917 & 105147 \\
\hline
\end{tabular}

without access), and Merridin (6752 people without access). Figure 1 provides a graphical representation of the locations of the current renal disease management service providers, and the ABS population concentrations.

The RFDS conducted 1636 aeromedical retrievals (1.6\% of the total aeromedical retrievals) for patients with renal disease, during the 2014 to 2018 financial years, as detailed in Table 1 . Most of the transfers were from rural and remote areas to inner-regional or metropolitan centres (Fig. 2). Data on the kilometres flown by each patient were collected on 1022 (62.5\%) of the patients; the average flight distance was $377.5 \mathrm{~km}(\mathrm{SD}=254.7)$. The majority $(n=965 ; 94.4 \%)$ of the aeromedical retrieval locations were more than $100 \mathrm{~km}$, with many $(n=481 ; 47.1 \%)$ being over $300 \mathrm{~km}$, from the nearest chronic disease management service, as detailed in Figure 3.

Among retrieved patients, there was a higher proportion of men than women $(P<0.01)$. Indigenous patients

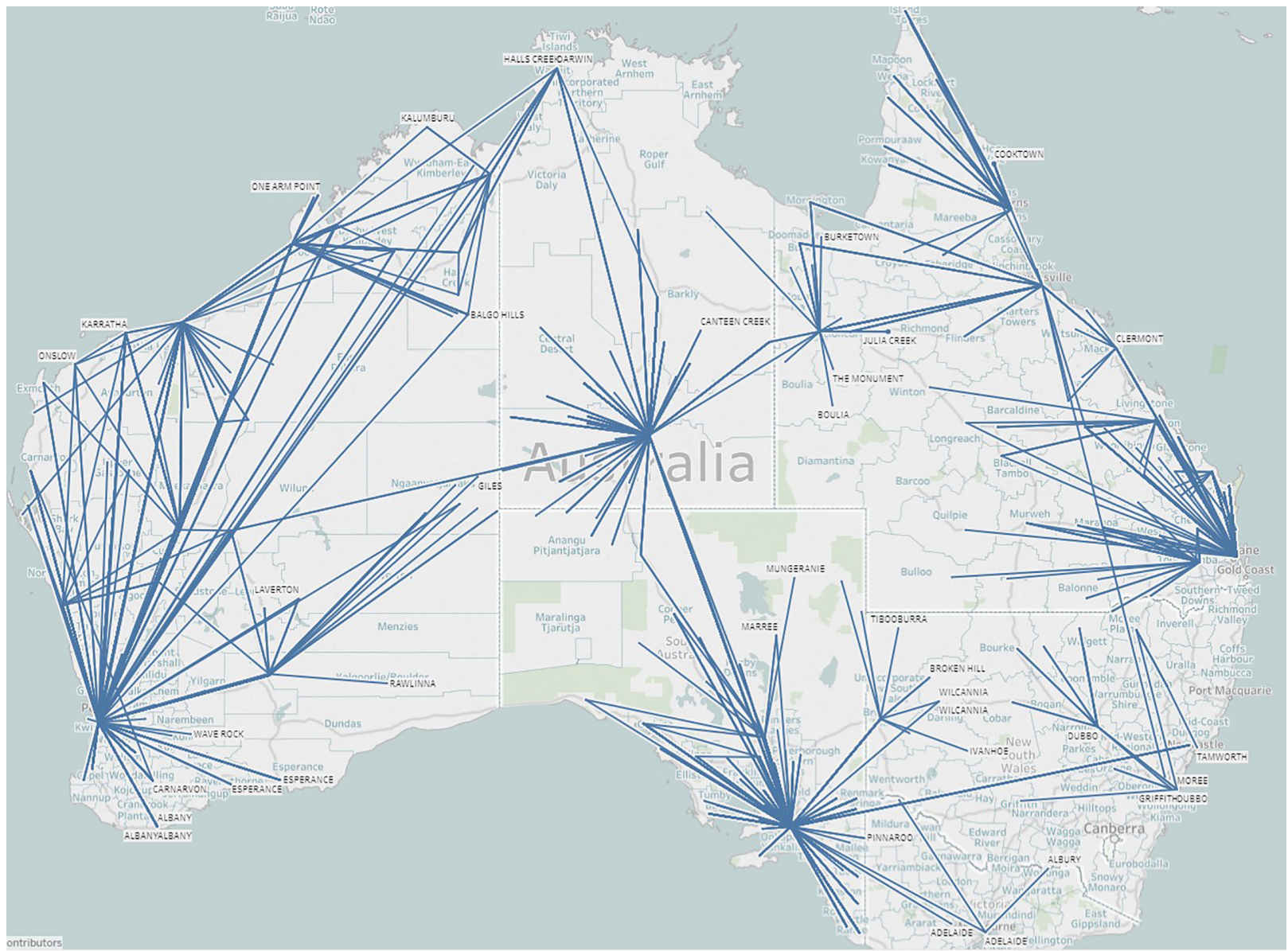

Figure 2 Chronic kidney disease aeromedical retrieval and transfer locations. 


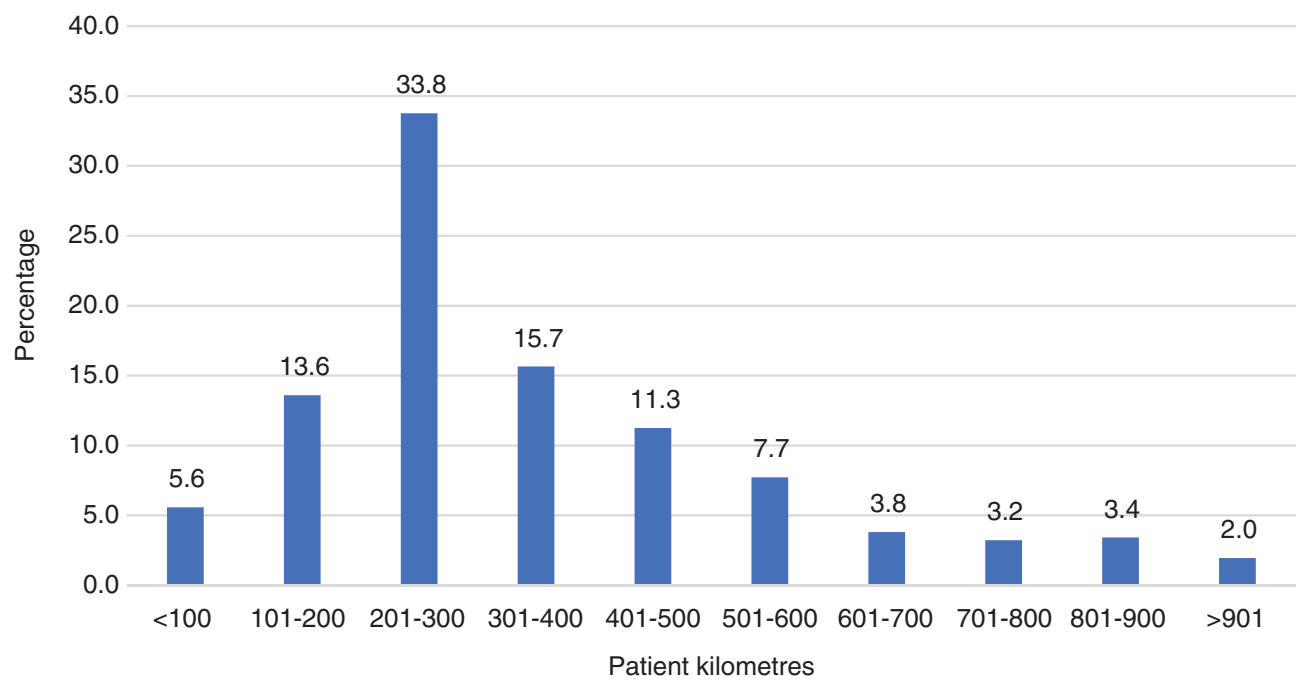

Figure 3 Patient aeromedical retrieval location and the distance to an appropriate treatment facility.

comprised over one-third of all retrievals (see Table 2). The average age of indigenous patients was 40.9 $(\mathrm{SD}=20.6)$ years which was significantly $(P<0.01)$ younger than that of the non-indigenous patients (average age of $58.5(\mathrm{SD}=19.1$ ) years). Age is described by diagnosis in Table 2.

Among retrieved patients, there were significant differences in diagnoses between genders, as shown in Table 2. Males were more likely (all $P<0.01$ ) than females to have a diagnosis of acute renal failure (acute kidney injury), calculus of the kidney and ureter, renal colic, obstructive uropathy, kidney failure, unspecified nephritic syndrome, calculus of the lower urinary tract, and recurrent and persistent haematuria. Conversely, females were more likely (all $P<0.01$ ) to have a diagnosis of chronic kidney disease, other disorders of kidney and ureter, acute nephritic syndrome, tubulo-interstitial nephritis, acute tubulo-interstitial nephritis, other renal tubulo-interstitial diseases, nephrotic syndrome, disorders resulting from impaired renal tubular function, and other disorders of kidney and ureter in diseases not classified elsewhere.

Indigenous patients were over-represented (all $P<0.01)$ as compared to non-indigenous patients in relation to transfers with diagnoses of chronic kidney disease, acute nephritic syndrome, tubulo-interstitial nephritis, and unspecified nephritic syndrome (refer to Table 2 for the full breakdown). Of concern, indigenous Australians who were retrieved for acute renal failure (acute kidney injury), chronic kidney disease, and kidney failure were significantly (all $P<0.01$ ) younger, aged 50.5 ( $S D=13.4)$, than non-indigenous Australians, aged $66.4(\mathrm{SD}=15.2)$, retrieved for the same conditions.

\section{Discussion}

Our findings show that there are large populations living in rural and remote regions of Australia who do not have access to specific renal disease management services within a reasonable driving distance, that is $60 \mathrm{~min}$. This lack of access is supported by the more common use of aeromedical retrieval services by people living in these rural and remote regions. Of particular concern is the high proportion of indigenous patients requiring an aeromedical retrieval for renal disease, and the younger age of indigenous versus non-indigenous patients.

General practitioners manage the majority of chronic conditions in Australia; however rural and remote areas have primary healthcare shortages, ${ }^{20}$ with large communities without reasonable access. ${ }^{21}$ Mapping demonstrated that the majority of the rural and remote population may not have regular access to specific renal disease management services, including dialysis services, with the majority of the population required to travel hundreds of kilometres. This is consistent with recently published literature on other health outcomes, which indicated shortages of mental health and primary healthcare services in rural and remote areas. ${ }^{14,22}$

The primary management for end-stage kidney disease is haemodialysis. Haemodialysis is physically and socially demanding with patients often requiring dialysis three times a week, while also adhering to medication regimens and dietary recommendations. ${ }^{23}$ Consistent with our findings, it has been reported that $50 \%$ of indigenous patients with end-stage kidney disease starting dialysis lived in regions without dialysis treatment facilities, ${ }^{24}$ with $75 \%$ of remote indigenous patients 
Table 2 Characteristics of patients who had a RFDS medical retrieval between 2014 and 2018

\begin{tabular}{|c|c|c|c|c|c|c|c|}
\hline ICD-10 code description & $\begin{array}{l}\text { Male, } \\
\%(n)\end{array}$ & $\begin{array}{l}\text { Female, } \\
\%(n)\end{array}$ & $\begin{array}{l}\text { Total, } \\
\%(n)\end{array}$ & $\begin{array}{l}\text { Indigenous, } \\
\quad \%(n)\end{array}$ & $\begin{array}{l}\text { Indigenous, } \\
\text { males, } \\
\%(n)\end{array}$ & $\begin{array}{l}\text { Non-indigenous } \\
\text { patients, mean } \\
\text { age (SD) }\end{array}$ & $\begin{array}{l}\text { Indigenous } \\
\text { patients, mean } \\
\text { age }(S D)\end{array}$ \\
\hline $\begin{array}{l}\text { N17 Acute renal failure (acute } \\
\text { kidney injury) }\end{array}$ & $25.9(231)$ & $20.1(149)$ & $23.2(380)$ & $33.4(127)$ & $47.2(60)$ & $66.0(15.7)$ & $48.9(14.6)$ \\
\hline $\begin{array}{l}\text { N20 Calculus of kidney and } \\
\text { ureter }\end{array}$ & $24.2(216)$ & $17.2(128)$ & $21.0(344)$ & $6.1(21)$ & $38.1(8)$ & $56.4(16.6)$ & $39.6(13.1)$ \\
\hline N18 Chronic kidney disease & $13.2(118)$ & $19.2(143)$ & $16.0(261)$ & $70.1(183)$ & $38.8(71)$ & $69.1(14.4)$ & $51.8(10.7)$ \\
\hline N23 Renal colic & $7.6(68)$ & $4.8(36)$ & $6.4(104)$ & $13.5(14)$ & $21.4(3)$ & $49.0(14.4)$ & $41.3(16.9)$ \\
\hline $\begin{array}{l}\text { N13 Obstructive and reflux } \\
\text { uropathy }\end{array}$ & $6.0(54)$ & $4.4(33)$ & $5.3(87)$ & $14.9(13)$ & $23.1(3)$ & $62.0(17.3)$ & $54.0(5.7)$ \\
\hline $\begin{array}{l}\text { N28 Other disorders of kidney } \\
\text { and ureter, not elsewhere } \\
\text { classified }\end{array}$ & $3.7(33)$ & $5.5(41)$ & $4.5(74)$ & $16.2(12)$ & $25.0(3)$ & $56.5(23.5)$ & $49.8(21.3)$ \\
\hline N00 Acute nephritic syndrome & $2.9(26)$ & $4.7(35)$ & $3.7(61)$ & $75.4(46)$ & $41.3(19)$ & $45.7(25.6)$ & $9.6(13.4)$ \\
\hline N19 Kidney failure & $4.1(37)$ & $2.8(21)$ & $3.5(58)$ & $41.4(24)$ & $41.7(10)$ & $64.3(12.3)$ & $49.4(22.3)$ \\
\hline $\begin{array}{l}\text { N12 Tubulo-interstitial } \\
\text { nephritis, not specified as } \\
\text { acute or chronic }\end{array}$ & $1.1(10)$ & $5.5(41)$ & $3.1(51)$ & $52.9(27)$ & $3.7(1)$ & $49.1(20.7)$ & $36.4(13.3)$ \\
\hline $\begin{array}{l}\text { N10 Acute tubulo-interstitial } \\
\text { nephritis }\end{array}$ & $1.0(9)$ & $4.2(31)$ & $2.4(40)$ & $42.5(17)$ & $5.9(1)$ & $50.0(5.7)$ & $29.0(8.5)$ \\
\hline $\begin{array}{l}\text { N15 Other renal } \\
\text { tubulo-interstitial diseases }\end{array}$ & $1.6(14)$ & $3.4(25)$ & $2.4(39)$ & 48.7 (19) & $15.8(3)$ & $47.6(22.2)$ & $38.1(23.7)$ \\
\hline $\begin{array}{l}\text { N05 Unspecified nephritic } \\
\text { syndrome }\end{array}$ & $2.0(18)$ & $1.6(12)$ & $1.8(30)$ & $60.0(18)$ & $61.1(11)$ & $47.0(19.8)$ & $9.0(3.5)$ \\
\hline N04 Nephrotic syndrome & $1.7(15)$ & $1.9(14)$ & $1.8(29)$ & $37.9(11)$ & $27.3(3)$ & $31.8(31.2)$ & $21.0(18.1)$ \\
\hline $\begin{array}{l}\text { N25 Disorders resulting from } \\
\text { impaired renal tubular } \\
\text { function }\end{array}$ & $1.2(11)$ & $1.6(12)$ & $1.4(23)$ & $26.1(6)$ & $33.3(2)$ & $53.3(17.5)$ & $31.3(19.4)$ \\
\hline $\begin{array}{l}\text { N29 Other disorders of kidney } \\
\text { and ureter in diseases } \\
\text { classified elsewhere }\end{array}$ & $1.1(10)$ & $1.6(12)$ & $1.3(22)$ & $22.7(5)$ & $20.0(1)$ & $59.5(27.4)$ & $50.5(27.6)$ \\
\hline $\begin{array}{l}\text { N21 Calculus of lower urinary } \\
\text { tract }\end{array}$ & $1.2(11)$ & $0.9(7)$ & $1.1(18)$ & $11.1(2)$ & $0.0(0)$ & $70.6(12.5)$ & $60.0(0.0)$ \\
\hline $\begin{array}{l}\text { N02 Recurrent and persistent } \\
\text { haematuria }\end{array}$ & $1.3(12)$ & $0.4(3)$ & $0.9(15)$ & $6.7(1)$ & $0.0(0)$ & $69.3(34.9)$ & 50.0 (n/a) \\
\hline Total & $54.6(893)$ & $45.4(743)$ & $100(1636)$ & $33.4(546)$ & $36.5(199)$ & $58.5(19.1)$ & $40.9(20.6)$ \\
\hline
\end{tabular}

All gender comparisons were significant, at $P=<0.01$.

required to relocate to access treatment. Conversely, $99.8 \%$ of non-indigenous patients requiring treatment live in regions with dialysis services. ${ }^{25}$ As such, it should be of little surprise that the survival rates of rural and remote indigenous patients are significantly lower than those in non-indigenous metropolitan populations. ${ }^{4}$ If cost-effective and culturally appropriate services, compared to the cost of an aeromedical retrieval (estimated to be AU\$8500.0), are provided to areas without renal treatment units, patient outcomes may be improved which could potentially reduce the need for organisations, such as the RFDS, to undertake emergency aeromedical retrievals for patients at crisis point.

This is the first study to consider the characteristics of patients who underwent an aeromedical retrieval for renal disease. A key finding is that Indigenous Australians make up a high proportion of the aeromedical retrievals for these conditions. This may not be surprising as the National Rural Health Alliance reports that the prevalence of end-stage kidney disease is much higher in rural and remote Australia, at 81.1 and 35.7 in very remote and remote areas respectively, compared to 19.9 per 100000 in major Australian cities. ${ }^{26}$ Furthermore, the Second Australian Atlas of Healthcare Variation (second Atlas), showed that kidney and urinary tract infections are more prevalent in Indigenous Australians, and that rural and remote populations generally have a higher prevalence than metropolitan areas. ${ }^{27}$ The literature also indicates that Indigenous Australians have eight times the rate of end-stage kidney 
disease compared with non-indigenous Australians, ${ }^{28}$ with many having an earlier onset of disease. ${ }^{29}$ Indigenous Australians are more likely to live in rural and remote regions. ${ }^{30}$ While the RFDS is a rural and remote service provider, it was expected that many of the aeromedical transfers would be for indigenous patients. However, this study highlights several concerning factors in rural and remote areas: the earlier age of onset of acute and chronic renal disease, the lack of access to renal services as well as to dialysis facilities, likely culminating in many patients either leaving their communities to receive treatment or foregoing treatment until crisis point, via aeromedical retrieval services. ${ }^{29}$

It has been reported that travelling satellite dialysis units provide similar medical outcomes, and perceived patient benefits, as compared to major hospital units. $^{31}$ The RFDS, like Purple House, is ideally placed to provide road-based travelling dialysis treatment via its current primary healthcare services. As per other recently established non-traditional interventions for dental and hearing services, ${ }^{22,32}$ the RFDS could target areas without current renal treatment options using a travelling service integrated into current chronic disease care, leveraging telemedicine capabilities. This would allow rural and remote patients to stay within their communities to access regular treatment, which is believed would then improve outcomes for patients with renal disease living in rural and remote areas.

This study was limited to RFDS patient data and as such did not include other rural and remote healthcare providers. While all diagnoses were collected, a limitation was that we were unable to code all the working diagnoses to the more detailed second ICD-10-AM level; only the patient's primary working diagnosis was recorded. Consequently, this study may under-represent the burden of illness and complexity of case retrieval by the RFDS. This study may also have under-represented renal disease management service provision, in that this study only included services registered on HealthDirect. Nevertheless, HealthDirect was the most robust national dataset available at the time of publication. By including Aboriginal Medical Services that conduct renal disease management, such as Purple House, ${ }^{33}$ some of this limitation may have been ameliorated.

Future research will be aimed at determining how many patients returned to their communities following retrieval, and their associated patient journey. We also hope to determine patient outcomes while in hospital, which should also help determine the reasons for some patients not returning to their community. Understanding the social impacts of removing patients from their communities will be of considerable importance.

Ideally, all Australians should have access to appropriate health services to ensure good health. The 'adequate' provision of renal services depends on the size as well as the age, sex and indigenous status of the population, in addition to the prevalence of renal disease. In reality, provision of services is constrained by competing priorities within limited funding. Better understanding factors such as the social, economic, and personal impact of aeromedical retrievals in rural and remote populations provides additional information to this consideration of competing priorities.

\section{Conclusion}

This study aimed to estimate the provision of dedicated renal disease management services, and the characteristics of patients who received an aeromedical retrieval for renal disease within rural and remote Australia. The majority of retrievals were from areas without regular access to renal disease management services, with many rural and remote patients required to travel extensive distances to access services. The majority of patients retrieved were male, with significant aeromedical diagnostic differences between genders. Indigenous Australians were significantly younger than the wider population, with a significant over-representation of patients with chronic kidney disease, acute nephritic syndrome, tubulointerstitial nephritis, cystitis and unspecified nephritic syndrome.

To reduce acute cases requiring aeromedical retrieval, policy inventions need to be established to encourage increased service provision of renal disease management and dialysis services. The RFDS, alongside its current primary healthcare travelling clinics, could provide roadbased travelling satellite dialysis units, which have been found to provide similar medical benefits to units provided in major hospitals. These proposed travelling units would target areas without current service provision, with high population prevalence of renal disease and its associated comorbidities, such as diabetes and hypertension. A RFDS travelling satellite dialysis unit could also reduce retrievals for renal emergencies through early intervention.

\section{Acknowledgement}

We acknowledge the employees and supporters of the RFDS who made this research possible. 


\section{References}

1 Cui X, Zhou X, L-l M, Sun T-W, Gardiner FW, Wang L-X. A nurse-led structured education program improves self-management skills and reduces hospital readmissions in patients with chronic heart failure: a randomized and controlled trial. Rural Remote Health 2019: 19: 5270.

2 Zhang P, Tao G, Anderson LA. Differences in access to health care services among adults in rural America by rural classification categories and age. Aust J Rural Health 2003; 11: 64-72.

3 Gardiner FW, Gale L, Ransom A, Laverty M. Looking ahead: responding to the health needs of country. Australians in 2028 - the centenary year of the RFDS. 2018 [cited 2019 Jan 15]. Available from URL: https://www. flyingdoctor.org.au/assets/documents/ RN064_Looking_Ahead_Report_D3.pdf

4 Australian Institute of Health and Welfare (AIHW). Australia's Health 2018. Australia's Health Series No. 16. AUS 221. Canberra: AIHW; 2018.

5 Australian Institute of Health and Welfare (AIHW). Australia's Health 2014. Canberra: AIHW; 2014

6 Australian Institute of Health and Welfare (AIHW). Australia's Health 2016. Australia's Health Series No. 15. Cat. No. AUS 199. Canberra: AIHW; 2016.

7 Australian Institute of Health and Welfare (AIHW). Rural \& Remote Health. Rural $\theta$ Remote Australians. 2017 [cited 2017 Sep 13]. Available from URL: https://www.aihw.gov.au/reportsstatistics/population-groups/ruralremote-australians/overview

8 Gardiner FW, Nwose EU, Bwititi PT, Crockett J, Wang L. Blood glucose and pressure controls in diabetic kidney disease: narrative review of adherence barriers and evidence of achievement. J Diabetes Complications 2018; 32: 104-12.

9 Medicinewise N. Epidemiology of High Blood Pressure in Australia. 2017 [cited 2017 Apr 23]. Available from URL: http://www.nps.org.au/conditions/ heart-blood-and-blood-vesselconditions/blood-pressure/for-healthprofessionals/high-blood-pressure-inaustralia

10 Australian Heart Foundation. High Blood Pressure Statistics. 2016 [cited 2016 Oct 26]. Available from URL: https://www. heartfoundation.org.au/about-us/what- we-do/heart-disease-in-australia/highblood-pressure-statistics

11 Australian Bureau of Statistics. National Health Survey: First Results 2014-15. ABS Cat. No. 4364.0.55.001. Canberra: ABS; 2015.

12 Hyde Z, Smith K, Flicker L, Atkinson D, Almeida OP, Lautenschlager NT et al. Mortality in a cohort of remoteliving Aboriginal Australians and associated factors. PLoS One 2018; 13: e0195030.

13 Teoh N, Bishop L, Gardiner F. Royal Flying Doctor Service: 90 years of unparalleled service. MJA InSight 2018; 39.

14 Gardiner FW, Coleman M, Teoh N, Harwood A, Coffee NT, Gale L et al. Aeromedical retrievals for mental health crises reflect low level of support services in rural and remote Australia. Med J Aust 2019; 211: 351-6.

15 Gardiner FW, Coleman M, Teoh N Harwood A, Coffee NT, Gale L et al. Aeromedical retrievals of people for mental health care and the low level of clinical support in rural and remote Australia. Med J Aust 2019; 211: 351-6.

16 Australian Bureau of Statistics. Australian Statistical Geography Standard (ASGS): Volume 5 - Remoteness Structure. 2016 [cited 2018 May 2]. Available from URL: http://www.abs.gov.au/ ausstats/abs@.nsf/Latestproducts/1270. 0.55 .005 Main \%20Features 15July\% 202016 ?opendocument 8 tabname $=$ Summary\&prodno $=1270.0 .55 .005 \delta$ issue $=$ July $\% 2020168$ num $=$ \&view $=$

17 Health Direct Australia. Who We Are. 2018 [cited 2018 Nov 13]. Available from URL: https://about.healthdirect. gov.au/

18 World Health Organization. International Statistical Classification of Diseases and Related Health Problems, Tenth Revision. 2016 [cited 2019 Jan 1]. Available from URL: https://icd.who.int/browse 10/ 2016/en

19 National Centre for Classification in Health. International Statistical Classification of Diseases and Related Health Problems, Tenth Revision, Australian Modification (ICD-10-AM).

20 Zwar N, Harris M, Griffiths R, Roland M, Dennis, Powell Davies G et al. A Systematic Review of Chronic Disease Management. 2006 [cited 2019 Feb 12]. Available from URL: https:// openresearch-repository.anu.edu.au/ bitstream/1885/119226/3/final_25 zwar_pdf_85791.pdf

21 Gardiner FW, Richardson AM, Bishop L, Harwood A, Gardiner E, Gale L et al. Health care for older people in rural and remote Australia: challenges for service provision. Med J Aust 2019; 211: 363-4.

22 Gardiner FW, Richardson A, Gale L, Bishop L, Harwood A, Lucas RM et al. Rural and remote dental care: patient characteristics and healthcare provision. Aust J Remote Health 2019 (in review).

23 Anderson K, Devitt J, Cunningham J, Preece C, Cass A. "all they said was my kidneys were dead": indigenous Australian patients' understanding of their chronic kidney disease. Med J Aust 2008; 189: 499-503.

24 Marley JV, Dent HK, Wearne M, Fitzclarence C, Nelson C, Siu K et al. Haemodialysis outcomes of Aboriginal and Torres Strait Islander patients of remote Kimberley region origin. Med $J$ Aust 2010; 193: 516-20.

25 Cass A, Cunningham J, Snelling P, Wang Z, Hoy W. Exploring the pathways leading from disadvantage to end-stage renal disease for indigenous Australians. Soc Sci Med 2004; 58: 767-85.

26 National Rural Health Alliance. Kidney Disease in Rural Australia. 2013 [cited 2019 Mar 6]. Available from URL: https://ruralhealth.org.au/sites/ default/files/publications/nrha-factsheet35.pdf

27 The Second Australian Atlas of Healthcare Variation. The Second Australian Atlas of Healthcare Variation. 2017 [cited 2018 Nov 23]. Available from URL: https://acsqhc.maps.arcgis. com/apps/MapJournal/index.html? appid $=63 \mathrm{e} 4 \mathrm{~b} 6 \mathrm{a} 73138444395 \mathrm{f} 762 \mathrm{fa} 3 \mathrm{a}$ $61 \mathrm{db} 8 \mathrm{~b}$

28 McDonald SP, Russ GR. Current incidence, treatment patterns and outcome of end-stage renal disease among indigenous groups in Australia and New Zealand. Nephrology (Carlton) 2003; 8: 42-8.

29 Preston-Thomas A, Cass A, O'Rourke P. Trends in the incidence of treated endstage kidney disease among indigenous Australians and access to treatment. Aust N Z J Public Health 2007; 31 419-21

30 Bishop L, Laverty M, Gale L. Providing Aeromedical Care to Remote Indigenous Communities. Canberra: Royal Flying Doctor Service of Australia; 2016. 
31 Roderick P, Armitage A, Nicholson T, Mehta R, Gerard K, Mullee M et al. A clinical and cost evaluation of hemodialysis in renal satellite units in England and Wales. Am J Kidney Dis 2004; 44: 121-31.
32 Royal Flying Doctor Service. Hear, Hear! RFDS is Delivering Hearing Assessment Services to Rural Parts of Queensland. 2017 [cited 2019 Feb 19]. Available from URL: https:// www.flyingdoctor.org.au/news/hear-hear- rfds-deliver-hearing-assessment-servicesro-rural-parts-queensland/

33 Purple House. About. 2019 [cited 2019 Apr 15]. Available from URL: https:// www.purplehouse.org.au/ 